\title{
An atypical presentation of high potassium renal secretion rate in a patient with thyrotoxic periodic paralysis: a case report
}

\author{
Mei-Lan Tu', Yu-Wei Fang ${ }^{1,2}$, Jyh-Gang Leu ${ }^{1,2}$ and Ming-Hsien Tsai ${ }^{1,2^{*}}$ (D)
}

\begin{abstract}
Background: Hypokalemia is one of the most common clinical electrolyte imbalance problems, and thyrotoxic periodic paralysis (TPP) is a leading cause of presentation to the emergency department. Low renal potassium secretion rates, a normal acid-base balance in the blood, and hyperthyroidism are the hallmarks of suspected TPP.

Case presentation: Here we report the case of a 36-year-old man who presented to the emergency department with a sudden onset of acute muscle weakness at $5 \mathrm{~h}$ prior to admission. Biochemistry tests revealed hypokalemia with hyperthyroidism and renal potassium wasting. TPP was initially not favored due to the presence of renal potassium wasting. However, his serum potassium level rebounded rapidly within several hours after potassium supplementation, indicating that the intracellular shifting of potassium ions was the main etiology for his hypokalemia. The early stage of TPP development may have contributed to this paradox.

Conclusion: Therefore, it is premature to rule out TPP based on the presentation of high renal potassium secretion rates alone. This finding may result in an incorrect impression being made in the early stage of TTP and may consequently lead to an inappropriate potassium supplementation policy.
\end{abstract}

Keywords: Hypokalemia, Renal potassium wasting, Thyrotoxic periodic paralysis, Hyperthyroidism, Paralysis

\section{Background}

Thyrotoxic periodic paralysis (TPP), a disorder that primarily affects the lower extremities, occurs due to excess thyroid hormone secretion, which causes an abrupt intracellular shift of potassium ions. However, hypokalemia with hyperthyroidism does not always indicate the diagnosis of TPP. Some case reports have previously stated that patients with hyperthyroidism who presented with renal potassium wasting had a final diagnosis other than TPP, such as chronic alcoholism [1] and primary aldosteronism $[2,3]$. Low renal potassium excretion, a normal acid-base balance in the blood, and hyperthyroidism are the hallmarks of TPP. However, in some conditions, TPP may present with high potassium secretion rates.

We highlight an atypical presentation of TPP with renal potassium wasting in the early stage of presentation. The

\footnotetext{
* Correspondence: chaosmyth.tw@gmail.com

'Division of Nephrology, Department of Internal Medicine, Shin-Kong Wu Ho-Su Memorial Hospital, 95, Wen-Chang Rd, Shih-Lin, Taipei 111, Taiwan (R.O.C.)

${ }^{2}$ Fu-Jen Catholic University School of Medicine, Taipei, Taiwan (R.O.C.)
}

early recognition of TPP is crucial to provide appropriate treatment and to avoid the risk of rebound hyperkalemia if high-dose potassium replacement is administered. Appropriate and timely management decrease morbidity, mortality, and healthcare expenditure.

\section{Case presentation}

A 36-year-old Chinese man without any systemic medical illnesses presented to our emergency department with a 5-h history of acute general weakness that occurred upon waking up. On the day prior to symptom onset, he suffered from the feeling of low-grade fever and ate heavily before sleeping. There was no history of recent strenuous exercise or diuretic use. He denied any history of palpitations, hand tremors, abdominal pain, diarrhea, body weight loss, and numbness of limbs. Neither he nor his family members had previously experienced any such attack.

On physical examination, his blood pressure was 121/ $63 \mathrm{mmHg}$, body temperature was $36.6{ }^{\circ} \mathrm{C}$, pulse rate was 102 beats per minute, and respiration rate was 18

(c) The Author(s). 2018 Open Access This article is distributed under the terms of the Creative Commons Attribution 4.0 International License (http://creativecommons.org/licenses/by/4.0/), which permits unrestricted use, distribution, and 
breaths per minute. The patient had decreased muscle power especially in the lower extremities (lower limbs: proximal muscles $2 / 5$ and distal muscles $4 / 5$; upper limbs: proximal muscles $4 / 5$ and distal muscles $5 / 5$ ), but there was no flaccid paralysis of the lower extremities or areflexia. Other physical examination findings were unremarkable. The results of biochemical studies conducted on admission are shown in Table 1. Marked hypokalemia $(2.2 \mathrm{mmol} / \mathrm{L})$ and mild hypomagnesemia $(1.8 \mathrm{mg} / \mathrm{dL})$ were prominent findings. Urine potassium excretion indicated renal potassium wasting [transtubular potassium gradient (TTKG): 7.02; and fractional excretion of potassium (FeK): 7.12]. Potassium supplementation was initiated with potassium chloride $(\mathrm{KCl})$ infusion $(20 \mathrm{mEq}$ of $\mathrm{KCl}$ in $500 \mathrm{~mL}$ of normal saline infused at a rate of $120 \mathrm{~mL} / \mathrm{h}$ ). The serum potassium level was corrected

Table 1 Serum and urine biochemistry at admission

\begin{tabular}{|c|c|}
\hline Parameter (reference range) & Value \\
\hline \multicolumn{2}{|l|}{ Plasma } \\
\hline $\mathrm{pH}(7.35-7.45)$ & 7.37 \\
\hline Bicarbonate (22-26 mmol/L) & 24.9 \\
\hline BUN (7-25 mg/dl) & 13 \\
\hline Creatinine $(0.5-1.3 \mathrm{mg} / \mathrm{dl})$ & 0.75 \\
\hline $\mathrm{Na}^{+}(133-145 \mathrm{mmol} / \mathrm{L})$ & 139 \\
\hline $\mathrm{K}^{+}(3.3-5.1 \mathrm{mmol} / \mathrm{L})$ & $2.2^{\mathrm{a}}$ \\
\hline $\mathrm{Cl}^{-}(96-108 \mathrm{mmol} / \mathrm{L})$ & 106 \\
\hline $\mathrm{Ca}^{++}(3.68-5.6 \mathrm{mg} / \mathrm{dl})$ & 4.47 \\
\hline Phosphate (2.5-5 mg/dl) & 4.9 \\
\hline Magnesium (1.9-2.7 mmol/L) & $1.8^{\mathrm{a}}$ \\
\hline Osmolality (278-305 mOsm/kg) & 302 \\
\hline TSH (0.35-4.94 ulU/ml) & $<0.0025^{a}$ \\
\hline T4, Free $(0.7-1.48$ ng/dl) & $1.8^{\mathrm{a}}$ \\
\hline T3 (0.58-1.59 ng/ml) & 1.4 \\
\hline Anti - TPO (0-5.61 IU/ml) & $<1.0$ \\
\hline TSH receptor antibody & $18.4 \%^{\mathrm{a}}$ \\
\hline \multicolumn{2}{|l|}{ Spot urine } \\
\hline $\mathrm{pH}(5-8)$ & 6.5 \\
\hline Creatinine (mg/dl) & 230 \\
\hline $\mathrm{Na}^{+}(\mathrm{mmol} / \mathrm{L})$ & 230 \\
\hline $\mathrm{K}^{+}(\mathrm{mmol} / \mathrm{L})$ & 48 \\
\hline $\mathrm{Cl}^{-}(\mathrm{mmol} / \mathrm{L})$ & 243 \\
\hline Osmolality (300-900 mOsm/kg) & 938 \\
\hline $\operatorname{TTKG}(<3)^{\mathrm{b}}$ & 7.02 \\
\hline $\mathrm{K}^{+} / \mathrm{Cr}(\mathrm{mmol} / \mathrm{mmol})(<2)^{\mathrm{b}}$ & 2.36 \\
\hline FeK $(<3 \%)^{\text {b }}$ & 7.12 \\
\hline
\end{tabular}

${ }^{a}$ Indicates abnormal values; ${ }^{\mathrm{b}}$ indicates reference range for normal renal response to hypokalemia. Abbreviation: BUN, blood urea nitrogen; $\mathrm{TSH}_{\text {, }}$ thyroid stimulating hormone; TPO, thyroid peroxidase; TTKG, transtubular potassium gradient; FeK, fractional excretion of potassium (from 2.2 to $3.8 \mathrm{mmol} / \mathrm{L}$ ) within $4 \mathrm{~h}$ via $\mathrm{KCl}$ replacement (total: $19.2 \mathrm{mEq}$ ). The hormonal profile, including low thyroid-stimulating hormone (TSH) $(<0.0025 \mathrm{uIU} / \mathrm{mL})$, elevated free tetraiodothyronine (T4) $(1.8 \mathrm{ng} / \mathrm{dL})$, and normal triiodothyronine (T3) $(1.4 \mathrm{ng} / \mathrm{mL})$, indicated hyperthyroidism. Because TPP was highly suspected due to the rapid resolution of hypokalemia despite high renal potassium excretion, an oral beta-blocker and anti-thyroid medication (propranolol, $10 \mathrm{mg}$ BID, and methimazole, $5 \mathrm{mg}$ BID) were prescribed for controlling the hyperthyroidism. Normal anti-thyroid peroxidase antibody $(<$ $1.0 \mathrm{IU} / \mathrm{mL}$ ) and high titers of thyroid-stimulating hormone receptor antibody (18.4\%) indicated Graves' disease. Thyroid sonogram revealed bilateral multinodular goiter (Fig. 1). Finally, he was discharged on day 3 of admission in a stable condition with normal serum potassium levels.

No hypokalemia was noted during the outpatient follow-up (at 9 days after discharge). Methimazole was continued to control his hyperthyroidism, and the dose was adjusted according to the thyroid function test findings. Moreover, no more muscle weakness episode occurred during the one-year follow-up in the outpatient department of endocrinology.

\section{Discussion}

The incidence of TPP is high in Asian men from the second to fourth decades of life, and the recently increasing incidence in Western countries is due to global immigration [4]. The muscle weakness and increased risk of irregular heartbeats observed in TPP result from markedly reduced levels of potassium in the bloodstream. Increased $\mathrm{Na}^{+} / \mathrm{K}^{+}$-ATPase activity leads to a shift of potassium into tissues and depletes the circulation. An acid-base imbalance is generally absent in TPP. Abnormality in ion channels due to genetic mutation is thought to cause a shift of potassium into cells. The main ones are the L-type calcium channel $\alpha 1$-subunit [5, $6]$ and potassium inward rectifier 2.6 [7, 8], and this condition is therefore classified as a channelopathy [7]. Under conditions of high thyroxine levels, channelopathy leads to shifts of potassium into cells. Hyperthyroidism also increases the levels of catecholamines in the blood, increasing $\mathrm{Na}^{+} / \mathrm{K}^{+}$-ATPase activity $[9,10]$. Increased carbohydrate intake, strenuous exercise, stress, and corticosteroids induce increased insulin levels, which activate $\mathrm{Na}^{+} / \mathrm{K}^{+}$-ATPase $[9,11,12]$. Additionally, male hormones increase $\mathrm{Na}^{+} / \mathrm{K}^{+}$-ATPase activity, and this explains why males are at a higher risk of TPP despite thyroid disease being more common in females [13-15].

The etiologies and differential diagnoses of hypokalemia are illustrated in Fig. 2. The urinary potassium excretion rate, blood acid-base status, and blood pressure are crucial to determine the cause of hypokalemic 


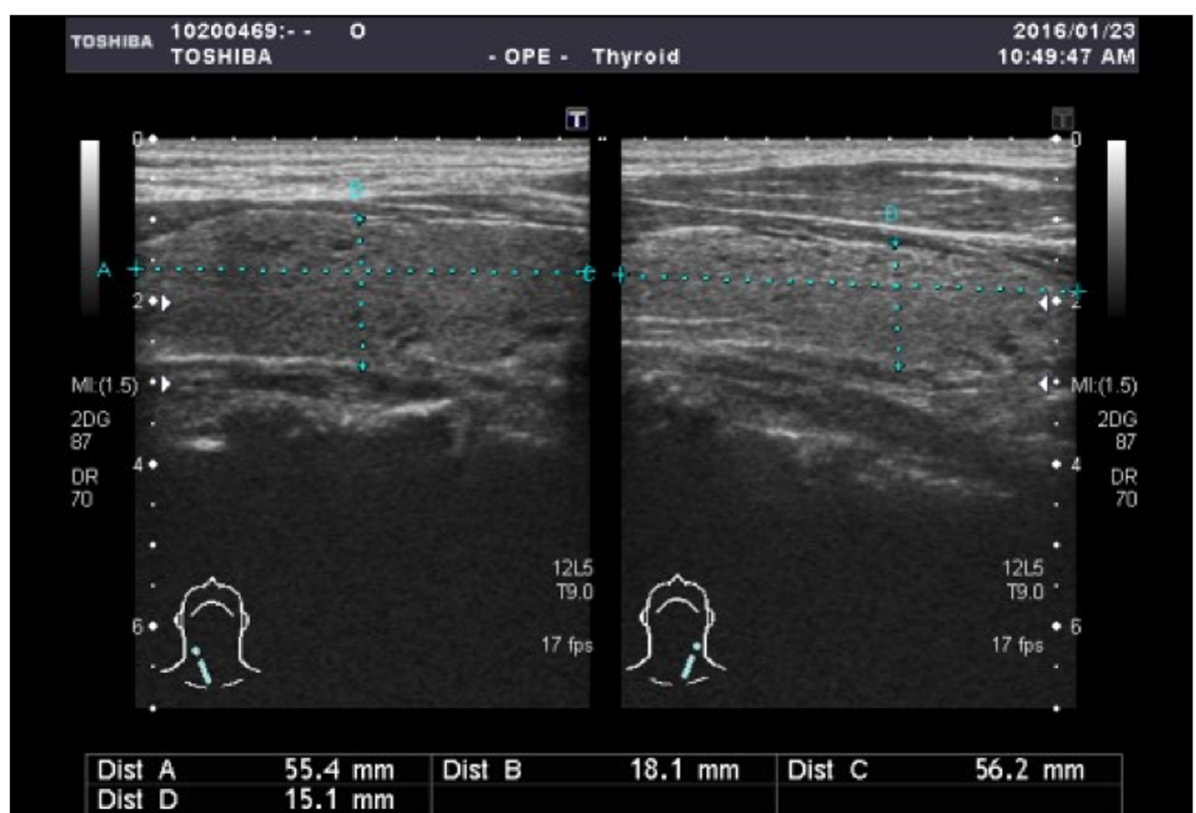

Fig. 1 Thyroid sonogram, Right thyroid: $5.62 \times 1.51 \mathrm{~cm}$, Left thyroid: $5.54 \times 1.81 \mathrm{~cm}$

paralysis. The urinary potassium excretion rate is assessed based on TTKG (reference: 3 ) or spot urinary potassium-creatinine ratio (reference: $2.0 \mathrm{mmol} / \mathrm{mmol}$ ). If a low urinary potassium excretion rate is noted, extrarenal loss or hypokalemic periodic paralysis should be considered. The blood acid-base status is relatively normal in TPP, whereas metabolic alkalosis or acidosis is observed in the presence of extrarenal causes, such as gastrointestinal disorders [16, 17]. If a high urinary potassium secretion rate is present, abnormal values of the blood acid-base status and blood pressure are useful clues. Coexisting metabolic acidosis suggests the

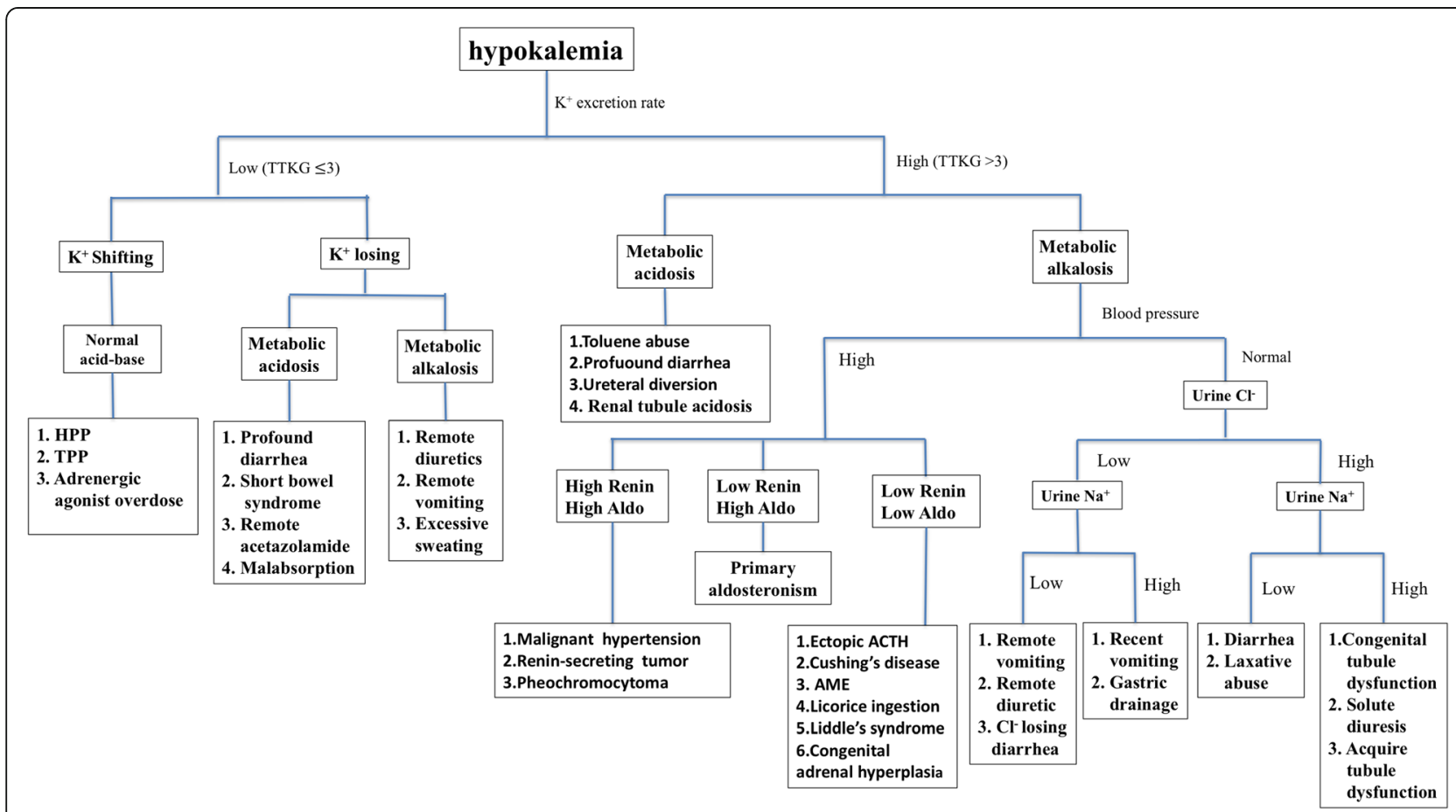

Fig. 2 The flow chart of approaching hypokalemia [1, 2, 16-20] 
presence of renal tubular acidosis, toluene use, severe diarrhea, or ureteral diversion. The presence of metabolic alkalosis with normal blood pressure advocates genetic renal tubulopathy (Gitelman syndrome and Bartter syndrome), severe diarrhea, vomiting, diuretic use, or acquired renal tubular dysfunction. The presence of metabolic alkalosis with hypertension indicates mineralocorticoid excess [1, 2, 18-20].

In the present case, the first spot urine analysis performed at the emergency department revealed a high urinary potassium excretion rate. There was no history of vomiting, diarrhea, or diuretic use. TPP was not favored despite hypokalemic paralysis with hyperthyroidism due to the presence of a high renal potassium excretion rate. However, the serially assessed serum potassium levels suddenly returned to within normal limits after several hours of potassium supplementation, indicating that the main etiology of his hypokalemia was intracellular potassium shifting. Moreover, the serum potassium level remained stable with the administration of a beta-blocker and methimazole. Low urinary phosphate excretion and hypercalciuria might further support the diagnosis of TPP. Though low urinary phosphate excretion and hypercalciuria can further support the diagnosis of TPP, we didn't have such information. However, the other clinical features and laboratory data had contributed the highly likelihood of TPP for our case and were consistent with a diagnosis of TPP by the flow chart of hypokalemia (Fig. 2).

We developed a hypothesis to describe this paradox: the renal potassium secretion rate does not rapidly reflect an early attack of TPP. Therefore, TPP cannot be ruled out based on the detection of high renal potassium wasting in the early presentation. This finding was an additional indicator that the provisional diagnosis of TPP was not excluded. One must be alert to diagnose TPP when faced with hypokalemia and hyperthyroidism despite high renal potassium wasting. A normal blood acid-base balance may be a hint for considering such a condition.

\section{Conclusion}

When facing a hypokalemic patient presenting with hyperthyroidism and renal potassium wasting, the impression of TPP should be taken into consideration because high renal potassium secretion may be observed in the early stage of TPP. Therefore, we should be cautious when prescribing potassium replacement to avoid rebound hyperkalemia in such a setting.

\section{Abbreviations}

FeK: Fractional excretion of potassium; $\mathrm{KCl}$ : Potassium chloride: T3: Triiodothyronine; T4: Tetraiodothyronine; TPP: Thyrotoxic periodic paralysis; TSH: Thyroid-stimulating hormone; TTKG: Transtubular potassium gradient
Funding

This research received no specific grant from any funding agency in the public, commercial, or not-for-profit sectors.

\section{Authors' contributions \\ MLT performed the clinical assessments and drafted the manuscript and table and was the major contributor in writing the manuscript. MHT and YWF performed the clinical assessments and assisted in drafting the manuscript. MHT was responsible for clinical care of the patient. MHT, YWF and JGL Co-reviewed and revised the manuscript critically for intellectual content. All authors read and approved the final manuscript.}

\section{Ethics approval and consent to participate}

Not applicable.

\section{Consent for publication}

Written informed consent was obtained from the patient for this publication of laboratory information and any accompanying images.

\section{Competing interests}

The authors declare that they have no competing interests.

\section{Publisher's Note}

Springer Nature remains neutral with regard to jurisdictional claims in published maps and institutional affiliations.

Received: 19 January 2018 Accepted: 26 June 2018

Published online: 04 July 2018

\section{References}

1. Tsai MH, Lin SH, Leu JG, Fang YW. Hypokalemic paralysis complicated by concurrent hyperthyroidism and chronic alcoholism: a case report. Medicine (Baltimore). 2015;94(39):e1689.

2. Hsiao YH, Fang YW, Leu JG, Tsai MH. Hypokalemic paralysis complicated by concurrent hyperthyroidism and Hyperaldosternoism: a case report. Am J Case Rep. 2017;18:12-6.

3. Yokota N, Uchida T, Sasaki A, Kobayashi K, Kida O, Yamamoto Y, Eto T, Tanaka K. Thyrotoxic periodic paralysis complicated with primary aldosteronism. Jpn J Med. 1991;30(3):219-23.

4. McFadzean AJ, Yeung R. Periodic paralysis complicating thyrotoxicosis in Chinese. Br Med J. 1967;1(5538):451-5.

5. Kung AW. Clinical review: Thyrotoxic periodic paralysis: a diagnostic challenge. J Clin Endocrinol Metab. 2006;91(7):2490-5.

6. Stedwell RE, Allen KM, Binder LS. Hypokalemic paralyses: a review of the etiologies, pathophysiology, presentation, and therapy. Am J Emerg Med. 1992;10(2):143-8.

7. Ryan DP, Ptacek L. Episodic neurological channelopathies. Neuron. 2010; 68(2):282-92.

8. Ryan DP, da Silva MR, Soong TW, Fontaine B, Donaldson MR, Kung AW, Jongjaroenprasert W, Liang MC, Khoo DH, Cheah JS, et al. Mutations in potassium channel Kir2.6 cause susceptibility to thyrotoxic hypokalemic periodic paralysis. Cell. 2010;140(1):88-98.

9. Ewart HS, Klip A. Hormonal regulation of the $\mathrm{Na}(+)-\mathrm{K}(+)$-ATPase: mechanisms underlying rapid and sustained changes in pump activity. Am J Phys. 1995;269(2 Pt 1):C295-311.

10. Chan A, Shinde R, Chow CC, Cockram CS, Swaminathan R. In vivo and in vitro sodium pump activity in subjects with thyrotoxic periodic paralysis. BMJ. 1991;303(6810):1096-9.

11. Vijayakumar A, Ashwath G, Thimmappa D. Thyrotoxic periodic paralysis: clinical challenges. J Thyroid Res. 2014;2014:649502.

12. Soonthornpun $\mathrm{S}$, Setasuban $\mathrm{W}$, Thamprasit A. Insulin resistance in subjects with a history of thyrotoxic periodic paralysis (TPP). Clin Endocrinol. 2009; 70(5):794-7.

13. Biering H, Bauditz J, Pirlich M, Lochs H, Gerl H. Manifestation of thyrotoxic periodic paralysis in two patients with adrenal adenomas and hyperandrogenaemia. Horm Res. 2003;59(6):301-4

14. Guerra M, Rodriguez del Castillo A, Battaner E, Mas M. Androgens stimulate preoptic area Na+,K+-ATPase activity in male rats. Neurosci Lett. 1987;78(1): 97-100

15. Pothiwala P, Levine SN. Analytic review: thyrotoxic periodic paralysis: a review. J Intensive Care Med. 2010;25(2):71-7. 
16. Chiang WF, Hsu YJ, Chang CC, Lin SH. Hypokalemic paralysis in a young obese female. Clin Chim Acta. 2012;413(15-16):1295-7.

17. Sung CC, Cheng CJ, Chiang WF, Chau T, Hsu YJ, Yang SS, Lin SH. Etiologic and therapeutic analysis in patients with hypokalemic nonperiodic paralysis. Am J Med. 2015;128(3):289-96. e281

18. Lin SH, Lin YF, Chen DT, Chu P, Hsu CW, Halperin ML. Laboratory tests to determine the cause of hypokalemia and paralysis. Arch Intern Med. 2004; 164(14):1561-6.

19. Lin SH, Chiu JS, Hsu CW, Chau T. A simple and rapid approach to hypokalemic paralysis. Am J Emerg Med. 2003;21(6):487-91.

20. Lin SH, Halperin ML. Hypokalemia: a practical approach to diagnosis and its genetic basis. Curr Med Chem. 2007;14(14):1551-65.

Ready to submit your research? Choose BMC and benefit from:

- fast, convenient online submission

- thorough peer review by experienced researchers in your field

- rapid publication on acceptance

- support for research data, including large and complex data types

- gold Open Access which fosters wider collaboration and increased citations

- maximum visibility for your research: over $100 \mathrm{M}$ website views per year

At BMC, research is always in progress.

Learn more biomedcentral.com/submissions 